Moya-Mata, I.; Ros, C. (2019). The Teacher of Physical Education in Primary Textbooks. Revista Internacional de Medicina y Ciencias de la Actividad Física y el Deporte vol. 19 (75) pp. 521-534 Http://cdeporte.rediris.es/revista/revista75/artmaestra1037.htm

DOI: 10.15366/rimcafd2019.75.009

\title{
ORIGINAL
}

\section{LA MAESTRA DE EDUCACIÓN FÍSICA EN LOS LIBROS DE TEXTO DE PRIMARIA}

\section{THE TEACHER OF PHYSICAL EDUCATION IN PRIMARY TEXTBOOKS}

\author{
Moya-Mata, I. ${ }^{1}$ y Ros, C. ${ }^{2}$ \\ 1 Profesora asociada de la Universidad de Valencia. Facultad de Magisterio. Departamento de \\ Didáctica de la Expresión Musical, Plástica y Corporal (España) irene.moya@uv.es \\ 2 Profesora Titular de la Universidad Católica de Valencia. Facultad de Ciencias de la Actividad \\ Física y el Deporte. Departamento de Gestión y Didáctica de la actividad física (España) \\ concepcion.ros@ucv.es
}

Código UNESCO /UNESCO code: 6309 Posición social de la mujer /Social position of women

Clasificación del Consejo de Europa/Council of Europe classification: 16. Sociología del deporte / Sociology of sport

Recibido 28 de agosto de 2017 Received August 28, 2017

Aceptado 9 de noviembre de 2017 Accepted November 9, 2017

\section{RESUMEN}

El objetivo del presente estudio es analizar cómo se representa a la maestra de educación física en los libros de texto de esta área, en la etapa de Educación Primaria. Se realiza un estudio cuantitativo que muestra un número elevado de maestras con respecto al maestro de educación física, principalmente en el primer ciclo de Primaria y otro cualitativo, a través del análisis de contenido, identificando un tratamiento estereotipado en cuanto a las características físicas de la docente, al representar a una maestra eminentemente joven, de raza blanca, delgada, con ropa deportiva y sin discapacidad. Pero a la vez, aparece un tratamiento más abierto y participativo en cuanto al rol representado, ya que la maestra de educación física aparece en la zona periférica de la imagen, con actitud activa, en un espacio no necesariamente deportivo, sin complementos docentes, que imparte contenidos relacionados con la gestión del grupo-clase y los juegos.

PALABRAS CLAVE: estereotipo, imagen, análisis de contenido, profesorado, libro de texto, educación física, educación primaria. 


\section{ABSTRACT}

The objective of the present study is to analyse how the physical education teacher is represented in the textbooks of this area, in the Primary Education stage. A quantitative study is carried out showing a high number of teachers with respect to the physical education teacher, mainly in the first cycle of Primary Education and a qualitative one, through content analysis, identifying a stereotyped treatment of the physical characteristics of the teacher, by representing a teacher eminently young, white, thin, wearing sports clothes and without disabilities. But at the same time, a more open and participative treatment appears in relation to the role represented, since the physical education teacher appears in the peripheral area of the image, with an active attitude, in a space not necessarily sports, without teaching complements, that Imparts content related to group-class management and games.

KEY WORDS: stereotype, image, analysis of content, teaching staff, textbook, physical education, primary school.

\section{INTRODUCCIÓN}

El libro de texto es definido por Rodrigues y Darido (2011) como un material íntimamente ligado al proceso de enseñanza-aprendizaje, con la intención de auxiliar las necesidades de planificación, intervención y evaluación del profesorado, así como la de contribuir en el aprendizaje del alumnado.

El libro de texto está formado por texto e imágenes, pero estas imágenes no son un mero recurso estético destinado a hacerlo más atractivo, sino que cumplen una función didáctica que complementa y facilita la comprensión de los conceptos o tareas que se proponen, y que han de servir de apoyo a los mensajes presentes en los textos; y en algunos niveles de enseñanza son la fuente de información prioritaria (Brugeilles y Cromer, 2009).

Por el tipo de lenguaje que manejan (icónico) son especialmente importantes para vehicular mensajes -con mucha frecuencia cargados de estereotipos- que, al ser recibidos a través de canales perceptivos y sensitivos, suelen escapar a un análisis consciente y explícito. De hecho, en Primaria, los dibujos, si bien expresan una imagen algo más alejada de la realidad, es el tipo de iconografía más representada en los libros de texto (Terrón y Cobano-Delgado, 2009).

En el caso de la Educación Física (EF) escolar, el libro de texto como material curricular es de reciente expansión si lo comparamos con el resto de materias escolares, ya que en esta área han dominado los recursos o medios técnicos ligados a las actividades físico-deportivas. Concretamente a partir de la Ley Orgánica General del Sistema Educativo (LOGSE), las editoriales muestran un interés mayor por este tipo de material impreso en el área de Educación Física, que hasta ese momento no requería textos para el alumnado (Molina, Valenciano y Úbeda-Colomer, 2016). 
En este material curricular se pueden encontrar diferentes tipos de estereotipos, que según Galán (2007) constituyen “(...) una imagen generalizada o aceptada comúnmente por un grupo -sobre otras personas o grupos-, que se transfiere en el tiempo, pudiendo adquirir la categoría de verdad indiscutible" (p.230).

En el caso de la actividad física y el deporte, diversos estudios muestran que podemos encontrar estereotipos en: las imágenes publicitarias de las revistas (López-Villar, 2011), en las portadas de los videojuegos (Ramírez-Macías, 2011) o en los libros de texto de EF, tanto en la etapa de Primaria (Moya, Ros, Bastida y Menescardi, 2013; Moya-Mata, Ruiz, Martín, Pérez y Ros, 2017) como en la etapa de Secundaria (González-Palomares, Táboas-Pais y Rey-Cao, 2017).

La imagen del profesorado de EF no es una excepción. Un sector significativo de la sociedad muestran una visión estereotipada de estos profesionales de la educación, pues piensan en una persona joven, con buen físico y extrovertida; además de configurar una imagen sobre el área de EF (Pérez, Rivera y Trigueros, 2014), muchas veces excesivamente simplificada y alejada de la realidad (Pérez-López, 2013). Asimismo, entre los estereotipos que envuelve la docencia, y concretamente la carrera universitaria de Magisterio se encuentra la feminización de este sector, que tal como señala Giró (2009) la constatación de una presencia mayoritaria de mujeres hay que entenderla "como el resultado de procesos interrelacionados de carácter histórico, sociológico, político, económico, religiosos y cultural" (p.17) aunque en el caso de la EF y el deporte ocurre lo contrario, persistiendo la masculinización en estos estudios (Porto, 2009).

Por lo que los libros de texto de EF pueden ser un gran referente para evaluar al profesorado como colectivo, desde un enfoque de autocrítica (Moya-Mata y Ros, 2015). Pero los estudios en España son escasos, encontrando solamente la investigación de Moya-Mata y Ros (2015), que analiza la imagen del docente de EF en los libros de texto de EF en la etapa de Primaria siendo fundamentalmente femenina.

Otros estudios afines al objeto de estudio son las series televisivas españolas, en donde se analiza la imagen del docente de EF (Galán, 2007; García-Muñoz y Fedele, 2013; González-Arévalo, 2006), con gran transcendencia en la conformación del imaginario colectivo en torno a la EF.

Concretamente, en el estudio de González-Arévalo (2006) la imagen del profesorado de EF que se representa en diferentes medios de comunicación es: “(...) negativa, retrógrada, injusta, descontextualizada y alejada de la realidad actual" (p.28), siendo el estereotipo del docente de EF en la televisión de: "chico o chica joven, guapo o guapa, alto o alta y cachas, que lleva ropa ajustada y ceñida. Como complemento indispensable para la ejecución de sus clases (...) lleva incluido en su pack de vestuario, silbato y cronómetro." (González-Arévalo, 2006, p.29).

En el estudio de Pérez et al. (2014), el docente de EF que se representa a partir de tres series españolas ("teen series"), recreadas en contextos escolares, se 
identifica con personas de baja formación intelectual, más preocupados por su apariencia externa: "(...) entre los 25 y 40 años, que destaca por su atractivo físico (...). Que se erigen en "modelos corporales" para sus alumnos y alumnas, causando su admiración" (p.863). Por lo que según esa imagen, la vida útil de un docente de EF no superaría los 45-50 años. Además de la masculinización de esta profesión, ya que de los cinco docentes de EF que aparecen en las series analizadas, una es mujer y cuatro son hombres.

A partir de estos estereotipos y tópicos relacionados con la EF y el docente, surge la inquietud y necesidad de comprobar si los libros de texto de EF de Primaria mantienen esta imagen, y concretamente con la maestra de EF.

Por lo que la finalidad de este estudio es analizar la imagen de la maestra de EF que se representa en los libros de texto y comprobar si continúa transmitiendo los estereotipos asociados a esta área, en la etapa de Educación Primaria. Dicha finalidad la podemos concretar en los siguientes objetivos:

- Analizar las características físicas de la maestra de EF en la selección de la muestra elegida.

- Detectar e identificar los estereotipos presentes en la imagen de la maestra de EF representada, a partir de las imágenes seleccionadas.

\section{MÉTODO}

El presente estudio se aborda tanto desde una perspectiva cuantitativa como cualitativa Por un lado se realiza un estudio empírico, descriptivo y comparativo (Heinemann, 2003) y frecuencial (Piñuel, 2002), utilizando el análisis de contenido como técnica central (Banks, 2010; Neuendorf, 2011). A su vez se realiza un estudio cualitativo, desde el cual se interpreta la realidad y se identifican la presencia o ausencia de estereotipos de género de la docente de EF (Gibb, 2012). Las imágenes que aparecen en los libros de texto de EF (fotografías y dibujos) son las unidades de muestreo.

\section{Muestra}

La muestra está formada por 45 imágenes de los libros de texto de EF en la etapa de EP, pertenecientes a seis editoriales españolas: Anaya, Bruño, Edelvives, Santillana, Serbal y Teide, en las que aparecía la figura del especialista de EF.

Los criterios de inclusión utilizados para la selección de este material curricular fueron: que estuvieran publicados en el Sistema Educativo Español, bajo el marco de la Ley Orgánica de Educación 2/2006 (más conocida como LOE), pertenecientes a la etapa de Primaria, en el área de EF y que en la imagen se pudiera identificar a una docente especialista en EF. 


\section{Instrumento de recogida de los datos}

El instrumento utilizado para el análisis de estas imágenes parte del sistema de categorías utilizado en el estudio de López-Crespo y Castejón-Oliva (2017) sobre el análisis de la mujer representada en la pintura deportiva y el sistema de categorías de Moya-Mata y Ros (2015) diseñado para analizar la figura del docente especialista representado en los libros de texto de EF.

La elaboración de dicho instrumento se realizó tras la reunión de un grupo de expertos (dos profesoras doctoras de la Facultad de Ciencias de la Actividad Física y el Deporte -de la Universidad Católica de Valencia-, un profesor de la Facultad de Ciencias de la Educación y un profesor de la Facultad de Magisterio -ambos de la Universidad de Valencia- y dos maestras de EF en activo, con una antigüedad de cinco años de servicio en Primaria). Una de las premisas fundamentales fue que la ficha facilitara, de manera sencilla y operativa, la valoración por parte de los observadores, de los diferentes elementos de análisis.

Una vez elaborado y validado el sistema de categorías por dichos expertos, se realizó una prueba piloto con diez imágenes, escogidas al azar, para comprobar la adecuación de dicho instrumento.

Para realizarla prueba piloto se eligió a tres personas para garantizar la confiabilidad de las observaciones, siendo el número mínimo de codificadores para el análisis de contenido dos personas (Neuendorf, 2011). El sistema de categorías final definió un conjunto de dimensiones, categorías y subcategorías utilizado para el análisis de estas imágenes (Tabla 1).

Tabla 1. Sistema de categorías para el análisis de la representación de la maestra de EF en los libros de texto de EF en la EP

\begin{tabular}{|c|c|c|}
\hline DIMENSIÓN & CATEGORÍAS & SUBCATEGORÍAS \\
\hline \multirow{3}{*}{$\begin{array}{l}\text { Características técnicas de } \\
\text { la imagen }\end{array}$} & Tipo de ilustración & $\begin{array}{l}\text { Dibujo } \\
\text { Fotografía }\end{array}$ \\
\hline & Color & $\begin{array}{l}\text { Color } \\
\text { Blanco y negro }\end{array}$ \\
\hline & Tamaño & $\begin{array}{l}\text { Muy grande } \\
\text { Grande } \\
\text { Mediano } \\
\text { Pequeño }\end{array}$ \\
\hline \multirow{5}{*}{$\begin{array}{l}\text { Características físicas del } \\
\text { docente }\end{array}$} & Edad & $\begin{array}{l}\text { Joven } \\
\text { Adulta }\end{array}$ \\
\hline & Raza & $\begin{array}{l}\text { Blanca } \\
\text { Negra } \\
\text { Latinoamericana } \\
\text { Otras }\end{array}$ \\
\hline & Somatotipo & $\begin{array}{l}\text { Ectomorfo } \\
\text { Endomorfo } \\
\text { Mesomorfo }\end{array}$ \\
\hline & Indumentaria & $\begin{array}{l}\text { Ropa deportiva } \\
\text { Ropa de calle }\end{array}$ \\
\hline & Discapacidad & $\begin{array}{l}\text { Con discapacidad } \\
\text { Sin discapacidad }\end{array}$ \\
\hline
\end{tabular}




\begin{tabular}{ll}
\hline Zona de la imagen & Central \\
& Periférica \\
\hline \multirow{2}{*}{ Espacio ocupado } & Deportivo \\
& No deportivo \\
& Medio natural \\
\hline Actitud & Activa \\
& Pasiva \\
\hline \multirow{2}{*}{ Complementos docentes del docente } & Silbato \\
& Cuaderno de notas \\
& Silbato y cuaderno de notas \\
& Ninguno \\
\hline & Capacidades perceptivo- \\
& motrices \\
& Expresivas \\
& Juegos \\
& En la naturaleza \\
& Complementarias \\
& Gestión del grupo-clase \\
\hline
\end{tabular}

El sistema de categorías consta de tres dimensiones: características técnicas de la imagen, características físicas del docente y rol del docente. En la dimensión relacionada con las características técnicas de la imagen se incluyen las categorías: (a) tipo de ilustración, establece el formato de la imagen impresa: dibujo y fotografía, (b) color o blanco y negro, y (c) tamaño de la imagen, que establece la dimensión de la imagen con respecto a la página del libro de texto: muy grande, si la imagen ocupa más de una página; grande, si la imagen ocupa dos tercios o más de la página; mediano, si la imagen ocupa entre uno o dos tercios de la página; y pequeño si la imagen ocupa menos de un tercio de la página.

En la dimensión características físicas del docente se incluyen las categorías: (a) edad, establece la etapa cronológica aproximada del personaje en la imagen: joven, cuya apariencia muestra una edad comprendida entre los 19 y los 35 años, y adulta, cuya apariencia muestra una edad entre los 36 y los 65 años, (b) raza, en función del color de la piel, los ojos o el ancho de la nariz: blanca, negra, latinoamericana y otras razas, (c) somatotipo, en relación a las características morfológicas de la persona representada según su predominio óseo, graso o muscular respectivamente: ectomorfo, endomorfo y mesomorfo, (d) indumentaria, que refleja el atuendo de las maestras representadas según sea: ropa deportiva, ropa de calle y otra, y por último, (e) discapacidad, en función de la presencia o ausencia de limitación tanto física, sensorial como mental: con discapacidad y sin discapacidad. Respecto a esta última categoría, dada la variedad de discapacidades existentes, que difícilmente se pueden apreciar en una ilustración (fotografía o dibujo) se recurre al paratexto.

Y la dimensión rol del docente se corresponde con el papel asignado a las docentes de EF, definida por categorías como: (a) zona de la imagen, en función del lugar que ocupa la figura de la maestra en la imagen: central so ocupa el centro de la imagen o periférica si ocupa zonas próximas a los bordes de la imagen, (b) espacio ocupado, según el entorno o ambiente físico que le rodea a la maestra: deportivo, si aparecen indicadores que reflejan un espacio destinado 
a la realización de prácticas deportivas, aunque no de un modo exclusivo, como por ejemplo campos de fútbol, pista polideportiva del colegio, gimnasio escolar, etc., no deportivo, si parecen indicadores que reflejan un espacio que no es de carácter deportivo, como por ejemplo un parque, y medio natural, si aparecen indicadores que reflejan un entorno natural, como por ejemplo: los árboles, la montaña, el mar o el río; poco modificado por el hombre, (c) actitud, aludiendo al estado de pasividad o actividad de la maestra: activa, si la docente representa la acción de algún movimiento, y pasiva si no representa movimiento alguno, ya sea de pie, sentada, etc., (d) complementos docentes, aquellos objetos que se relacionan con la docencia de EF, como son: silbato, cuaderno de notas, silbato y cuaderno de notas y ninguno, y por último, (e) contenido impartido, referente a cualquier contenido del área de EF representado en la imagen: capacidades perceptivo-motrices, derivadas y dependiente del sistema nervioso central, como son: el esquema corporal, la espacialidad y la temporalidad; y de la combinación de éstas surgen otras intermedias como: la lateralidad, el ritmo, la estructuración espacio-temporal, el equilibrio y la coordinación (Castañer y Camerino, 1992), expresivas, actividades que utilizan el cuerpo como medio de expresión desde una perspectiva estética, como son: la expresión corporal, el mimo, las sombras chinescas, la dramatización, la danza y el baile, los juegos, aquellos que tienen como característica fundamental la aceptación libre de reglas sencillas, modificables y adaptadas al grupo, incluyendo los juegos populares y tradicionales, en la naturaleza, actividades denominadas de multiaventura, que se desenvuelven en las tres superficies: tierra, agua y aire, como por ejemplo: bicicleta de montaña, escalada, esquí, orientación, parapente, senderismo, surf, windsurf, etc., complementarias, en donde se representan actividades de valoración y/o medición, tales como la toma de pulsaciones, la talla, el peso, etc.; o de tests, como los de condición física, y por último, gestión del grupo-clase, en donde se representan otras acciones relacionadas con la práctica docente de $E F$, como son: las explicaciones de los juegos, las normas, las rutinas, la presentación de nuevo alumnado al grupo-clase o los primeros auxilios, entre otros.

\section{Procedimiento}

En primer lugar se seleccionaron las imágenes en donde aparecía la figura de un docente especialista en EF, desechando aquellas que contenían imágenes de otro profesorado y las que no contenían esa presencia. Dichas imágenes se incluyeron en una plantilla Excel para facilitar los datos sobre el porcentaje del análisis cuantitativo que se utilizó para esta fase del estudio.

A continuación se seleccionaron las imágenes en las que había representación de especialistas de EF femeninas, para realizar el análisis cualitativo según el sistema de categorías anteriormente señalado.

\section{ANÁLISIS ESTADÍSTICO}

Una vez obtenidos los datos de la muestra se realizó un análisis descriptivo de frecuencias, con la finalidad de conocer y representar de forma clara y precisa los resultados de esta investigación. A continuación se realizó un análisis cualitativo de la representación femenina en la figura del especialista de EF. El 
tratamiento de la información se realizó mediante el programa IBM SPSS versión 23.0 .

\section{RESULTADOS Y DISCUSIÓN}

Si bien, como se comentó anteriormente, solo contamos con un estudio de la representación de la figura del docente en los libros de texto de EF (Moya-Mata y Ros, 2015), nos referiremos para la discusión, a los resultados de investigaciones similares en las series televisivas españolas (González-Arévalo, 2006; Pérez et al., 2014).

En las características técnicas de la imagen, el "tipo de ilustración" que predomina en las imágenes analizadas son viñetas dibujadas y a color (100\%). Este predominio del dibujo frente a la fotografía y en color es generalizado en la etapa de Primaria, tanto en las áreas de Matemáticas, Conocimiento del Medio Natural, Social y Cultural y Lengua (López-Manjón y Postigo, 2016; Terrón y Cobano-Delgado, 2008, 2009), como en el área de EF (Moya, Ros, Menescardi y Bastida, 2015), aunque difiere del estudio de Moya-Mata et al. (2017) sobre las imágenes relacionadas con la discapacidad, en las que predomina la fotografía frente al dibujo.

En relación al "tamaño de la imagen" predomina el tamaño pequeño $(55,17 \%)$, frente al grande $(27,58 \%)$ y al mediano (17,25\%), respectivamente. Estos resultados coinciden con estudios similares en EF (Moya-Mata y Ros, 2015; Moya et al., 2015; Moya-Mata et al., 2017). Según García y Ponsoda (1997), las imágenes de mayor tamaño y a color (Aparici, García-Mantilla, Fernández y Osuna, 2009) captan mayor atención en el receptor que aquellas de menor tamaño y en blanco y negro. En este estudio, el predominio de las imágenes pequeñas supone un predominio del texto sobre la imagen, que a su vez, parece equilibrarse con la totalidad de las imágenes a color, otorgando mayor expresividad y fijación por parte del lector (Aparici et al., 2009; López y Castañer, 2006).

Respecto al ciclo educativo al que pertenecen las imágenes analizadas comprobamos que el primer ciclo el que más representación tiene la maestra de EF (62\%), seguido del segundo ciclo $(24,27 \%)$ y el tercer ciclo de Primaria $(13,8 \%)$. Esto coincide con el estudio de Moya-Mata y Ros (2015) en donde la representación del docente es mayor en el primer ciclo y va disminuyendo a medida que el ciclo educativo es superior. No podemos olvidar que el acceso de la mujer a la profesión de maestras en el siglo XIX se hace como una extensión de sus labores de maternidad y cuidado, convirtiendo la profesión docente, en las primeras etapas, en una especia de maternidad (Ballarín, 2001). La generalización en el contexto social de la idea de la enseñanza como una versión de la maternidad constituyó la base para la feminización de la profesión docente (Giro, 2009).

De las 45 imágenes analizadas, 29 representaron la figura de la maestra especialista en EF, es decir, el 64,4\% de las imágenes; siendo Anaya la editorial con mayor número de imágenes, con un $22,2 \%$, y Bruño la que menos, al no 
representar ninguna imagen en la que apareciera el especialista de EF (Tabla 2).

Tabla 2. Imágenes de los docentes de EF en las editoriales españolas

\begin{tabular}{cccc}
\hline EDITORIAL & $\begin{array}{c}\text { IMÁGENES } \\
\text { DOCENTES EF }\end{array}$ & $\begin{array}{c}\text { IMÁGENES } \\
\text { MAESTRAS EF }\end{array}$ & $\begin{array}{c}\text { \% IMÁGENES } \\
\text { MAESTRAS EF }\end{array}$ \\
\hline Anaya & 12 & 10 & 22,2 \\
Bruño & 0 & 0 & 0 \\
Edelvives & 2 & 2 & 4,4 \\
Santillana & 6 & 1 & 2,2 \\
Serbal & 15 & 7 & 15,6 \\
Teide & 10 & 9 & 20,0 \\
Total & $\mathbf{4 5}$ & $\mathbf{2 9}$ & $\mathbf{6 4 , 4}$ \\
\hline
\end{tabular}

Este resultado coincide con el estudio previo de Moya-Mata y Ros (2015) respecto a la mayor representación femenina del docente de EF frente a la masculina en los libros de texto de EF en EP, pero contradice el estudio de Porto (2009), en el que afirma que los estudios sobre actividad física y deporte están masculinizados. En esta línea, este resultado nada tiene que ver con el modelo masculino que se refleja del docente de EF, en diversas series de televisión españolas analizadas por González-Arévalo (2006) y Pérez et al. (2014). Por lo tanto estamos ante un paso más en cuanto a la coeducación y la igualdad de oportunidades de ambos sexos en algunas editoriales. Tal y como propugna la LOE en uno de sus principios y fines educativos, que fomenta la igualdad efectiva entre hombres y mujeres, y la igualdad de derechos. En la misma línea, la Ley Orgánica $3 / 2007$, para la igualdad efectiva de hombres y mujeres, señala en su artículo 24 entre otras acciones, el principio de igualdad y la eliminación y el rechazo de los comportamientos y contenidos sexistas y estereotipos entre mujeres y hombres, con especial consideración a los materiales educativos.

Respecto a las características físicas de la maestra de EF, la "edad" que se representa es joven en el $100 \%$ de las imágenes. Este predominio de la juventud coincide con el estudio de Moya-Mata y Ros (2015) de los docentes de EF en los libros de texto, y los estudios de González-Arévalo (2006) y Pérez et al. (2014) en las series televisivas españolas analizadas. Esto pensamos que es debido a la idea de juventud, como ideal de belleza, que transmite la televisión, como mensaje subliminal. Sin duda la existencia de estereotipos negativos sobre las personas mayores, influye en su escasa presencia en las imágenes que aparecen en los libros de texto de Primaria.

Si analizamos la "raza" observamos que el 100\% de las maestras de EF representadas son de raza blanca. Este resultado coincide con la imagen del docente que aparece tanto en los libros de texto de EF (Moya-Mata y Ros, 2015), como en las series televisivas españolas (González-Arévalo, 2006; Pérez et al., 2014). Por tanto, parece que en esta profesión no hay cabida para los docentes de diferente raza a la blanca, aún cuando en la actualidad, la situación demográfica en España revela un contexto multirracial. Según datos aportados por el Instituto Nacional de Estadística (INE, 2016), los datos provisionales 
señalan que la población extranjera residente en España supone el 9,5\% de la población, siendo mayor el porcentaje en años anteriores (en 2014 supuso el $10,7 \%$, en 2013 el $11,7 \%$ y en 2012 el $12,1 \%$ de la población).

Igualmente existe un $100 \%$ de la constitución delgada o ectomorfa de la maestra de EF, vestida con ropa deportiva; dato que coincide con el estudio del docente de EF en Primaria (Moya-Mata y Ros, 2015).

Respecto a la representación de la "discapacidad", el 100\% de las imágenes analizadas representa a una maestra de EF sin discapacidad, coincidiendo con la representación de los docentes de EF (Moya-Mata y Ros, 2015) y en las series de televisión españolas (González-Arévalo, 2006; Pérez et al., 2014). Esta invisibilización de la discapacidad en las series de televisión basadas en contextos educativos, y concretamente en los libros de texto de EF no favorece la inclusión de este colectivo en la sociedad, y mucho menos en el ámbito educativo. Aún cuando existe un porcentaje de plazas reservadas a personas con discapacidad en las oposiciones de distintos cuerpos docentes y especialidades. De hecho, uno de los retos que propone el Fondo de las Naciones Unidas para la Infancia (2013), para reducir los estereotipos y prejuicios que tiene la población general sobre la diversidad física, mental y sensorial, es cambiando la escuela tradicional por inclusiva; y este reto debería ampliarse también a los profesionales del ámbito educativo, ya que como propone la ONU (2006) sobre la discapacidad, los Estados deben promover la toma de conciencia respecto de las capacidades y aportaciones de las personas con discapacidad.

Respecto al rol docente asignado a la maestra de EF en los libros de texto, en cuanto a la zona de la imagen ocupada, principalmente es periférica $(65,5 \%)$ frente a la zona central o primer plano $(34,5 \%)$, predominante en el estudio de López-Crespo y Castejón-Oliva (2017) sobre la representación femenina en las pinturas deportivas.

El análisis del espacio ocupado por las imágenes, muestra que el $62,1 \%$ de las imágenes representa a la maestra de EF en un espacio no deportivo, frente al espacio deportivo $(27,6 \%)$ o el medio natural $(10,3 \%)$. Esto nos da a entender que la función de la maestra de EF es más didáctica que deportiva, en las imágenes.

Con una actitud eminentemente activa $(86,2 \%)$ frente a la actitud pasiva de mera espectadora (13,8\%), como prevalece en la mitad de las obras del estudio de López-Crespo y Castejón-Oliva (2017). Por lo que se representa a una maestra de EF participativa, dialogante y controlando el proceso de enseñanzaaprendizaje del grupo-clase continuamente.

Además, el especialista de EF suele aparecer con símbolos o complementos docentes, como es el caso de un silbato junto con el cronómetro o una libreta de anotaciones, tanto en los libros de texto de EF (Moya-Mata y Ros, 2015), como en las series de televisión españolas analizadas (González-Arévalo, 2006). En este estudio, la maestra de EF se representa principalmente sin complementos 
docentes $(51,7 \%)$, seguida de silbato y cuaderno de notas $(24,2 \%)$, sólo con cuaderno de notas $(17,2 \%)$ y por último, sólo con silbato colgado del cuello (6,9\%). Este resultado se aleja del estereotipo tradicional del docente de EF asociado a un silbato, un cronómetro y una libreta de anotaciones, centrado más en el resultado que en el proceso, a partir de determinados tests y pruebas de rendimiento, muy alejado de la EF actual.

Por último, el contenido impartido que más se asocia a la maestra de EF representada en los libros de texto de EF es el relacionado con la gestión del grupo-clase (35\%), como por ejemplo, las normas del área de EF, y entre otras, la obligación de realizar la sesión con la ropa y calzado adecuado (Figura 1). Seguido de los juegos (31\%), las capacidades perceptivo-motrices (13,8\%), las actividades en la naturaleza (10,3\%), las actividades complementarias $(6,9 \%)$ y las actividades expresivas (3,5\%). Resultado que difiere del estudio de Moya, Ros y Menescardi (2014) en donde se comprueba que la actividad física más representada en los libros de texto de EF en la etapa de Primaria es la condición física, al igual que en las series televisivas españolas (López-Pérez, 2013).

Por un lado muestra que el área de EF rompe con esa imagen tradicional y mecanicista, más preocupada del rendimiento que del proceso pedagógico; pero por otro lado, mantiene la idea de que existen contenidos "masculinos", como es el caso de los deportes, que a su vez gozan de mayor prestigio social, y son impartidos exclusivamente por maestros de EF y no por maestras. Desaprovechando la oportunidad de incidir en el fomento de hábitos saludables de vida y/o actividad física mediante la EF, al igual que ocurre en las series televisivas españolas (López-Pérez, 2013), aun siendo conscientes de las graves consecuencias que tiene el sedentarismo entre la población infantil y adolescente (Strasburger, Jordan y Donnerstein, 2010).

\section{CONCLUSIONES}

La representación de la maestra especialista en los libros de texto de EF en la etapa de Primaria permite por un lado, conocer qué imagen se proyecta de este sector de la docencia, y por otro, conformar en el alumnado su percepción sobre la asignatura.

La representación de la maestra de EF presenta por un lado, estereotipos tradicionales relacionados tanto con las características físicas de éstas, al mostrarla exclusivamente joven, de raza blanca, delgada, con ropa deportiva y sin discapacidad; como por el rol representado: ubicada en zonas periféricas de la imagen, en espacios no deportivos, impartiendo contenidos relacionados con el juego y aspectos actitudinales como las normas, vinculadas con la gestión del grupo-clase.

En cambio, la actitud con la que se representa supone una ruptura con los estereotipos más tradicionales relacionados con la asignatura de $\mathrm{EF}$, ya que se muestra con actitud activa, controlando y participando de la sesión de EF junto a su alumnado, y sin complementos docentes. Por lo que se rompe con esa 
visión tradicional del área de EF deportiva y enfocada al rendimiento, en donde el especialista de EF lleva colgado un silbato y un cuaderno de notas.

Estos resultados nos motivan a abrir una nueva línea de investigación, que ya se aborda desde otros medios de comunicación como es el caso de la televisión, por las implicaciones educativas que conlleva, ya que los libros de texto es un material educativo y pedagógico, presente en la mayoría de los centros educativos, que contribuye en la formación de las identidades profesionales y los estereotipos en torno a éstas.

Las limitaciones de este estudio y sus conclusiones deben entenderse desde una muestra de los libros de texto de EF en la etapa de Primaria, publicados bajo la LOE. Como futuras líneas de estudio se proponen analizar los libros de texto de EF publicados bajo la LOMCE y/o de otras etapas educativas.

\section{REFERENCIAS BIBLIOGRÁFICAS}

Aparici, R., García-Matilla, A., Fernández, J. y Osuna, S. (2009). La imagen. Análisis y representación de la realidad. Barcelona: Gedisa.

Ballarín, P. (2001). La educación de las mujeres en la España Contemporánea (siglo $X I X-X X)$. Madrid: Síntesis

Banks, M. (2010). Los datos visuales en investigación cualitativa. Madrid: Morata.

Brugeilles, C. y Cromer, S. (2009). Promoting gender equality through textbooks. A methodological guide. Recuperado de http://unesdoc.unesco.org/images/0015/001588/158897E.pdf

Fondo de las naciones unidas para la infancia (UNICEF, 2013). Informe Mundial Sobre la Discapacidad. Nueva York: UNICEF.

Galán, E. (2007). Construcción de género y ficción televisiva en España. Comunicar, 28, 229-236.

García, C. y Ponsoda, V. (1997). Las características de los anuncios y la televisión. Estudios sobre consumo, 41, 85-100.

García-Muñoz, N. y Fedele, M. (2013). Las series televisivas juveniles: tramas y conflictos en una "teen series". Comunicar, 19(37), 133-140. https://doi.org/10.3916/C37-2011-03-05

Gibbs, G. (2012). El análisis de datos cualitativos en investigación cualitativa. Madrid: Morata.

Giró, J. (2009). Mujer y educación. Las maestras. Un análisis sobre la identidad de género y trabajo. Logroño: Instituto de Estudios Riojanos. Ayuntamiento de Logroño

González-Arévalo, C. (2006). La educación física en la televisión: "Cuéntame cómo pasó". Tándem: Didáctica de la Educación Física, 21, 28-35.

González-Palomares, A., Táboas-Pais, Mạ . I. y Rey-Cao, A. (2017). La cultura corporal en función del género: Análisis de los libros de texto de educación física de secundaria publicados durante la ley orgánica de educación. Educación $X X 1$, 20(1), 141-162. https://doi.org/10.5944/educxx1.17506

Heinemann, K. (2003). Introducción a la metodología de la investigación empírica. Barcelona: Paidotribo. 
Instituto Nacional de Estadística (INE, 2016). Cifras de Población a 1 de enero de 2016 y Estadística de Migraciones del año 2015. Datos Provisionales. Recuperado de http://www.ine.es/prensa/np980.pdf

Ley Orgánica 2/2006, de 3 de mayo, de Educación. Boletín Oficial del Estado, 4 de mayo de 2006. № 106. España.

Ley Orgánica 3/2007, de 22 de marzo, para la igualdad efectiva de mujeres y hombres. España. Boletín Oficial del Estado, 23 de marzo de 2007. № 71. España.

López, C. y Castañer, M. (2006). Investigar la lectura de la imagen fija publicitaria con relación al cuerpo y la actividad física. Tándem. Didáctica de la Educación Física, 21, 8-16.

López-Crespo, C. y Castejón-Oliva, F.J. (2017). Mujer y pintura deportiva: la colección del Consejo Superior de Deportes (España). Revista Internacional de Medicina y Ciencias de la Actividad Física y el Deporte, 17(65), 101-119. https://doi.org/10.15366/rimcafd2017.65.007

López-Manjón, A. y Postigo, Y. (2016). ¿Qué libro de texto elegir? La competencia visual en las actividades con imágenes. Revista Eureka sobre Enseñanza y Divulgación de las Ciencias, 13(1), 84-101. https://doi.org/10.25267/Rev Eureka ensen divulg cienc.2016.v13.i1.07

López-Villar, C. (2011). El cuerpo deportivo en las imágenes publicitarias de revistas. Madrid: Bubok Publishing.

Molina, P., Valenciano, J. y Úbeda-Colomer, J. (2016). El diseño curricular de la Educación Física en España: Una revisión crítica desde la LOGSE a la LOMCE. Cultura_Ciencia_Deporte, 11(32), 97-106. https://doi.org/10.12800/ccd.v11i32.710

Moya, I., Ros, C., Bastida, A. y Menescardi, C. (2013). Estereotipos de sexo y raza en las imágenes de los libros de texto de educación física en primaria. Retos: Nuevas Tendencias en Educación Física, Deporte y Recreación, 23, 14-18. Recuperado de http://www.retos.org/numero 23/23-3.html

Moya, I., Ros, C. y Menescardi, C. (2014). Los contenidos de educación física a través de las imágenes de los libros de texto de EP. Apunts, Educación Física y Deportes, 4(118), 40-47. $\quad$ https://doi.org/10.5672/apunts.20140983.es.(2014/4).118.04

Moya-Mata, I. y Ros, C. (2015). La imagen del docente de Educación Física en los libros de texto. Revista Opción, 31(5), 625-641. Recuperado de http://www.redalyc.org/html/310/31045570036/

Moya, I., Ros, C., Menescardi, C. y Bastida, A. (2015). Características técnicas y formales de la iconografía en libros de texto de Educación Física. Revista Electrónica Interuniversitaria de Formación del Profesorado, 18(3), 55-67. https://doi.org/10.6018/reifop.18.3.195801

Moya-Mata, I., Ruiz, L., Martín, J., Pérez, P. Mํa y Ros, C. (2017). La representación de la discapacidad en las imágenes de los libros de texto de Educación Física: ¿inclusión o exclusión? Retos. Nuevas tendencias en Educación Física, Deporte y Recreación, 32, 88-95. Recuperado de https://recyt.fecyt.es/index.php/retos/article/view/52191

Neuendorf, K. (2011). Content analysis: A methodological primer for gender research. Sex Roles, 64, 276-289. https://doi.org/10.1007/s11199-010-9893-0

Organización de Naciones Unidas (ONU, 2006). Convención sobre los derechos de las personas con discapacidad. Nueva York: ONU. 
Pérez-López, I.J. (2013). La educación física en las series de televisión españolas: ¿ficción o realidad? Revista Internacional de Medicina y Ciencias de la Actividad Física y el Deporte, 13(50), 199-216. Recuperado de http://cdeporte.rediris.es/revista/revista50/arteducacion380.pdf

Pérez, I., Rivera, E. y Trigueros, C. (2014). Imaginario social de la Educación Física construido desde las "teen series" de televisión españolas. Movimento. 20(3), 853-873. https://doi.org/10.22456/1982-8918.42764

Piñuel, J.L. (2002). Epistemología, metodología y técnicas del análisis de contenido. Estudios de Sociolingüística, 3(1), 1-42. Recuperado de http://web.jet.es/pinuel.raigada/A.Contenido.pdf

Porto, B. (2009). Feminización y masculinización en los estudios de maestro y educación física en Galicia. Revista de Investigación en Educación, 6, 50-57. Recuperado de http://webs.uvigo.es/reined/.

Ramírez-Macías, G. (2011). Estereotipos corporales en las portadas de los videojuegos de género deportivo. Revista Internacional de Medicina y Ciencias de la Actividad Física $y$ el Deporte, 42, 407-420. Recuperado de http://www.redalyc.org/html/542/54222171011/

Rodrigues, H.A. y Darido, S.C. (2011). O livro didático na Educação Física escolar: a visão dos professores. Motriz, 17(1), 48-62. https://doi.org/10.5016/19806574.2011v17n1p48

Strasburger, V., Jordan, A. y Donnerstein, E. (2010). Health effects of media on children adolescents. Pediatrics, 125(4), 756-767. https://doi.org/10.1542/peds.20092563

Terrón, MำT. y Cobano-Delgado, V. (2008). El papel de la mujer en las ilustraciones de los libros de texto de educación primaria. Foro De Educación, 10, 385-400. Recuperado de http://forodeeducacion.com/ojs/index.php/fde/article/view/166

Terrón, Mํㅜ․ y Cobano-Delgado, V. (2009). El papel de la mujer en las imágenes de los libros de texto de Educación Primaria. Estudio comparado entre España y Marruecos. Educatio Siglo XXI, 27(1), 231-248. Recuperado de http://revistas.um.es/educatio/article/view/71161

Número de citas totales / Total references: 37 (100\%) Número de citas propias de la revista / Journal's own references: $3(8 \%)$

Rev.int.med.cienc.act.fís.deporte - vol. 19 - número 75 - ISSN: 1577-0354 